\title{
A ATIVIDADE DISCENTE NA UNIVERSIDADE: CARACTERIZAÇÃO DOS ESTUDANTES E IMPACTOS DA PRODUTIVIDADE ACADÊMICA ${ }^{1}$
}

\author{
LA ACTIVIDAD DEL ALUMNADO EN LA UNIVERSIDAD: \\ CARACTERIZACIÓN DE LOS ESTUDIANTES E IMPACTOS DE LA \\ PRODUCTIVIDAD ACADÉMICA
}

\section{THE STUDENT'S ACTIVITY IN UNIVERSITY: CHARACTERIZATION OF STUDENTS AND ACADEMIC PRODUCTIVITY IMPACTS}

\author{
Maísa Aparecida OLIVEIRA ${ }^{2}$ \\ Maria Cristina Silveira Galan FERNANDES ${ }^{3}$
}

\begin{abstract}
RESUMO: $O$ artigo analisa o perfil e o impacto da produtividade acadêmica na formação dos estudantes universitários. Utilizou-se a aplicação de 120 questionários a estudantes de graduação pertencentes a três Centros de Ciências de uma IFES, sendo analisados com o processo de categorização dos conteúdos semânticos fundamentados em perspectivas críticas. Os dados revelam que há maior índice de participação em eventos científicos e programas de iniciação científica, o que corrobora a concepção da maior valorização da pesquisa. Ao mesmo tempo, a formação social, cultural e política do estudante estão deficitárias, considerando a baixa inserção nos grupos formais e informais e o pequeno índice de realização de estágios. Este fato pode sinalizar uma possível ampliação do individualismo fundamentado na competição no campo universitário.
\end{abstract}

PALAVRAS-CHAVE: Ensino superior. Produtividade acadêmica. Discente. Socialização.

RESUMEN: El artículo analiza el perfil y el impacto de la productividad académica en la formación de los estudiantes universitarios. Se realizó la aplicación de 120 cuestionarios a estudiantes de grado pertenecientes a tres Centros de Ciencias de una IFES. Fueron analizados con el proceso de categorización de los contenidos semánticos con soporte en perspectivas críticas. Los datos revelan que hay mayor índice de participación en eventos científicos y programas de iniciación científica, lo que confirma el concepto de la mayor valorización de la investigación. A la vez, la formación social, cultural y política del estudiante están deficitarias, considerando la baja inserción en los grupos formales e informales y el pequeño índice de realización de prácticas curriculares supervisadas. Ello puede señalizar una posible ampliación del individualismo con base en la competencia en el ámbito universitario.

PALABRAS CLAVE: Enseñanza superior. Productividad académica. Alumnado. Socialización.

${ }^{1}$ Este artigo é uma versão revisada e ampliada do texto apresentado com o mesmo título na $36^{\mathrm{a}}$ Reunião Anual da ANPED.

${ }^{2}$ Doutoranda em Educação pela Universidade Federal de São Carlos (UFSCar). É mestre em Educação pela UFSCar e licenciada em Pedagogia pela Universidade Federal de Viçosa. Email: maisavrb@hotmail.com

${ }^{3}$ Doutora em Educação pela Unesp/Araraquara. Docente do Programa de Pós-Graduação em Educação UFSCar. Email: cristinagfer@ufscar.br 
ABSTRACT: This paper analyzes the profile and the impact of academic productivity in university students' training. The application of questionnaires to 120 undergraduate students from three IFES Sciences centers was carried out and analyzed based on the process of semantic categorization supported by critical perspectives. The data reveal that there is a high index of participation in scientific events and programs for undergraduate research, which confirm the valuation of scientific research. Although this, the social, cultural and political formation of student is deficient, considering the low participation in formal and informal groups, and the low index of traineeship. This fact may indicate a possible expansion of individualism based on competition on campus.

KEYWORDS: Higher Education. Academic productivity. Student. Socialization.

\section{Introdução}

O presente artigo tem como objeto de investigação a atividade discente na universidade, tendo como foco a análise da caracterização dos universitários e a reflexão sobre a sua produtividade acadêmica. Tal temática aponta a necessidade de repensar a atividade discente na atual conjuntura da universidade e sua função social, bem como a formação do estudante, construída no cotidiano das relações estabelecidas entre aluno e a produtividade acadêmica.

Neste artigo buscamos refletir sobre parte dos dados de nossa pesquisa de mestrado referentes ao perfil dos estudantes universitários e suas atividades, visando compreender os impactos da produtividade acadêmica na formação dos estudantes.

A pesquisa apresenta caráter qualitativo e está sendo realizada em uma Instituição Federal de Ensino Superior (IFES). Os cursos selecionados foram: Biotecnologia, Fisioterapia, Ciências Biológicas, Medicina, Engenharia de Materiais, Engenharia Química, Física, Matemática, Pedagogia, Educação Especial, Filosofia e Ciências Sociais, pertencentes aos Centros de Ciências relacionados às áreas Biológicas, Humanas e Tecnológicas.

Para desenvolver a pesquisa foram convidados 40 estudantes de cada centro de ciências, sendo 10 estudantes de cada curso de graduação citado anteriormente, totalizando 120 voluntários. A amostra de participantes foi composta por estudantes matriculados nos dois últimos anos letivos, pois se entende que eles possuem experiência suficiente para tratar a temática proposta, pelo distanciamento temporal do ingresso e pela experiência acadêmica já adquirida. 
A coleta de dados foi realizada por meio da aplicação de questionário, apresentando-se, neste, questões objetivas e discursivas, recorrendo-se a procedimentos de análise quantitativos e qualitativos, buscando as regularidades e divergências nas opiniões da amostra e, assim, a categorização dos resultados obtidos (TRIVIÑOS, 2011).

Consideramos que a temática proposta possa contribuir para a ampliação das discussões sobre as mudanças que vêm ocorrendo no espaço universitário brasileiro, particularmente no que se refere aos estudantes, uma vez que são poucas as pesquisas realizadas sobre o discente que busquem caracterizá-lo no contexto da atual conjuntura de mudança do capitalismo flexível no Ensino Superior e compreender seu processo de socialização e formação acadêmica.

\section{A universidade e sua função social}

Compreende-se que o período atual de regulação do capitalismo designa, em um contexto de exigências diferenciadas, demandas e desafios à educação, de maneira peculiar à educação superior, incluindo os processos de internacionalização e globalização da economia. O modo de produção capitalista tem como princípio primeiro de sustentação a necessidade de permanentes transformações para um mercado cada vez mais competitivo. Assim, há uma maneira específica de compreensão da ampliação do capital estabelecida nas relações com o trabalho, nas quais a ciência e a tecnologia são concebidas como força de produção numa lógica racional que tem como paradigma os princípios da economia privada.

A universidade vem perdendo suas características seculares, tornando-se instituição administrativa, que atua de acordo com um conjunto de normas, planejamento e êxito. Nesse sentido, Chauí (2001) argumenta que a universidade, como entidade administrativa, descaracterizada de sua função social e autoavaliativa, torna-se instituição que se pauta nas noções de produtividade, estruturada por estratégias de eficácia organizacional. Desse modo, não mais se priorizam a construção do conhecimento e a formação intelectual, visto que o foco da universidade passou a ser a mera reprodução do conhecimento, bem como a absorção deste, que é aplicado de acordo com as exigências mercadológicas, exigências essas que passam a regular as relações entre seus atores sociais, incidindo em suas motivações, atitudes e expectativas. 
Nesse sentido, a universidade precisa atuar de maneira que o ensino ministrado, a pesquisa desenvolvida e os serviços de extensão atendam às exigências dos novos tempos, na perspectiva de enfrentamento dos problemas da estrutura socioeconômica vigente.

A produtividade acadêmica, como política de Estado e de cultura institucional, tem em sua tradução, na esfera filosófica, o pragmatismo, e na esfera econômica, a mercadorização da ciência e da inovação tecnológica. Nesse sentido, a produtividade acadêmica tem se tornado o polo gerador de uma reforma da instituição universitária que tende a colocá-la no reboque do mercado, mediante os programas de incentivo à pesquisa e desenvolvimento que beneficia as empresas de capital nacional e internacional (SGUISSARDI, SILVA JÚNIOR, 2009).

Os governos e empresários esperam que a universidade devolva à sociedade pessoas preparadas para acompanhar as necessidades e mudanças do mercado de trabalho e a necessidade econômica de maneira eficiente (CABRITO, 2004). Nesse sentido, existe ainda a expectativa de que o sistema educacional, como padrão hegemônico, possa preparar consumidores-cidadãos para novos tipos de produtos fomentados pela indústria cultural.

Diante do exposto é preciso repensar as saídas para a universidade enquanto instituição social e, de modo específico, os dilemas da universidade pública brasileira. Nesta pesquisa, em que se busca conhecer os impactos que as mudanças de identidade e das relações universitárias têm sobre a formação do aluno universitário, os autores Silva Jr., Sguissardi, Silva (2010) são fundamentais e levantam a proposição de que não podemos nos assustar se encontrarmos alunos da graduação necessitando de ansiolíticos para irem à universidade e narcolépticos para dormir.

Em face das considerações apresentadas, no que se refere às funções atribuídas à universidade e à sua relação com a sociedade e seus agentes, considera-se importante a discussão dos impactos do capitalismo flexível na instituição educativa de ensino superior, particularmente a questão de como a produtividade, no contexto universitário, atua sobre o desenvolvimento da formação acadêmica do discente. Nesse sentido, a formação do discente universitário é construída no cotidiano das relações estabelecidas entre aluno e a produtividade e a dimensão mercadológica da atividade científica.

\section{O estudante universitário e a produtividade acadêmica}


Os estudos e discussões sobre os estudantes universitários são fundamentais nesta pesquisa. Vários estudos (PACHANE, 2003; JOLY, SANTOS, SISTO, 2005; TEIXERA, WOTHICH, OLIVEIRA, 2008) abordam, de diferentes maneiras, o desenvolvimento dos estudantes inseridos no ensino superior, os quais são influenciados pelas experiências que têm enquanto universitários. Os aspectos condicionantes e formativos nesse contexto são as atividades acadêmicas, tais como as aulas, os estágios, as pesquisas, os projetos de extensão, grupos de pertença gerados pelo convívio na universidade, entre outros. No entanto, os impactos que tais atividades acarretam no universitário podem apresentar diferentes níveis de desenvolvimento ou de mudança, ainda que vivenciem as mesmas experiências acadêmicas.

Em pesquisa realizada por Oliveira e Saraiva (2010), as autoras estudaram o ofício da discência na universidade, buscando compreender os processos institucionais e psicossociais envolvidos na construção do ser e do fazer na discência. As autoras concluíram que a discência aparece associada às funções do aprender, do conhecer e do produzir, limitadas pelas demandas curriculares instituídas. Ao se instituir nesse contexto interrelacional que promove a individualidade, concorrência e competição entre os estudantes, exige-se, dos mesmos, um desempenho excepcional, aliado à competência e às inovações tecnológicas e acadêmicas.

Outros estudos interpelam a questão da produtividade acadêmica. Oliveira (2004); Silva, Silva Jr. (2011); Sguissardi, Silva Jr. (2008), têm realizado pesquisas que abordam a temática da produtividade acadêmica, objetivando compreender o processo de mercantilização da universidade estatal pública brasileira, estudando o trabalho e a formação do docente pesquisador. De forma mais específica, nesta pesquisa destaca-se o trabalho de Silva Jr. (2008), quando analisa, no contex to universitário, os alunos como co-produtores do processo educativo, pois exercem a condição de participantes do processo, sendo, ao mesmo tempo, objeto do trabalho humano (do professor) e sujeito da ação na formação universitária. Em publicação posterior, Silva, Silva Jr. (2011) afirmam que na pós-graduação, em razão do processo de avaliação ser predominantemente externo, os alunos tendem a sair do domínio do professor. Ao passo que os alunos na graduação estão mais atrelados ao controle dos professores sobre o processo de ensino.

Também Bourdieu nos apresenta reflexões relevantes sobre as inter-relações entre o universo simbólico incorporado pelos estudantes universitários e suas condições materiais e sociais de existência. O referido autor considera que as ações dos agentes 
educativos demandam problematização, no que se refere às inter-relações entre suas construções simbólicas e a conservação de dominação social, fazendo-se necessário analisar suas origens e as classificações sociais. A trajetória escolar é influenciada pelo contexto social no qual o indivíduo está inserido, o que determina o êxito ou o fracasso futuro, além da perspectiva de acesso à universidade.

No processo de incorporação da herança cultural e social, o conceito de habitus é postulado por Bourdieu como referência das predisposições duráveis do modo de agir, pensar e portar-se dos indivíduos. O habitus é incorporado nas relações estabelecidas socialmente, caracterizadas nas predileções e nas aptidões dos indivíduos (NOGUEIRA; NOGUEIRA, 2002).

Ressalta-se que sobreposições do habitus podem ocorrer como consequência da inserção do indivíduo no decorrer de sua trajetória em contextos histórico-culturais diferenciados. O habitus adquirido pelo indivíduo norteia suas ações determinando as escolhas e atitudes no desenvolvimento da formação pessoal e profissional.

Bourdieu considera ainda que a universidade é o principal instrumento de (re) produção das classes médias e superiores. Acrescenta que a preponderância na instituição educativa é exercida por meio de uma violência simbólica, partilhada inconscientemente entre dominador e dominado, determinada pelos esquemas práticos do habitus (BOURDIEU, 2002). Nesse sentido, a condição social e econômica do estudante universitário, nosso objeto de estudo, se reproduz objetivamente nos processos de socialização, de formação e de atuação do mesmo.

Portanto, Bourdieu nos revela elementos e categorias para análise dos dados obtidos neste trabalho, no que se refere à influência da família no processo de socialização e formação do estudante universitário, à inserção dos discentes nos diversos grupos sociais e científicos que a universidade proporciona, às suscetíveis modalidades de relações estabelecidas entre os pares universidade-estudantes, professores-estudantes e estudantes-estudantes e, por fim, identificar a participação (e a não participação) dos estudantes em atividades acadêmicas.

\section{Caracterização, socialização e produtividade acadêmica dos estudantes}

O questionário utilizado para a coleta das informações sobre os estudantes foi composto por questões referentes aos dados pessoais, tais como nacionalidade, sexo, idade e estado civil; dados socioeconômicos, indagando o nível de escolaridade dos pais, a renda familiar e a renda do participante; trajetória de escolarização: a escola 
frequentada nos ensinos fundamental e médio (se particular ou pública), modalidade de ensino médio cursado, se usufruiu de Ações Afirmativas para ingressar ao ensino superior, se integrou algum grupo informal de estudantes na universidade (Bateria, Esportes, Religiosos), ou Diretório Acadêmico (DCE, CA), se participou de Iniciação Científica, de Projeto de Extensão e de Eventos Científicos. Perguntou-se, ainda, sobre a produtividade acadêmica, se o aluno teve alguma publicação, se o participante considera que poderia ter mais publicações, como avalia sua produção acadêmica e, por fim, se participou de estágios curriculares e/ou extracurriculares.

Os resultados obtidos permitiram verificar que o perfil dos estudantes que participaram da pesquisa apresenta a média das idades compreendida em 23,08 anos. Este dado é confirmado pela investigação de Cardoso e Sampaio (1994), na qual, considerando os mesmos períodos letivos da presente investigação, obtiveram a média das idades dos estudantes universitários de 23,6 anos.

Quanto aos dados relativos ao sexo, $57,5 \%$ dos estudantes se declaram do sexo feminino. Os dados são validados pela pesquisa realizada por Guedes (2008) que revela um aumento expressivo de mulheres cursando o ensino superior, superando a presença masculina neste nível de ensino. Ao se considerar os dados divididos por Centro de Ciências percebe-se que a maior presença feminina no ensino superior está localizada na área de Humanas, bem como na área Biológica, em que também há predominância feminina. Já a área Tecnológica continua predominantemente masculina.

Os dados obtidos nos questionários revelaram ainda que os estudantes, em sua maioria, são solteiros. Em relação à nacionalidade, verificou-se que um estudante se declarou japonês.

A perspectiva do futuro escolar do estudante é construída socialmente e submetida às condições materiais e sociais de existência (BOURDIEU, 1975). As predisposições de incorporação do habitus tem como referência a herança dos capitais cultural e social. Assim, a escolarização dos pais, como detentores da herança cultural e social transmitida aos filhos (estudantes pesquisados), influencia na aspiração dos níveis de ensino auferidos pelos filhos.

Considerando-se os dados gerais referentes aos 112 estudantes que responderam ao questionário foi possível constatar, em relação à escolaridade dos pais, que: 5,8\% dos pais possuem Pós-Graduação, 40,7\% possuem Ensino Superior Incompleto/Completo, 24,1\% possuem Ensino Médio Incompleto/Completo, 21,6\% possuem Ensino Fundamental Incompleto/Completo e $0,83 \%$ é Analfabeto. Observa-se que só há pais 
analfabetos no Centro de Educação e Ciências Humanas e essa unidade acadêmica possui o menor número de pais com ensino superior completo.

Em relação à escolaridade das mães, dos 116 estudantes que responderam à questão, constatou-se que 6,8\% das mães possuem Pós-Graduação, 43\% possuem Ensino Superior Incompleto/Completo, 33,5\% possuem Ensino Médio Incompleto/Completo, 15,5\% possuem Ensino Fundamental Incompleto/Completo e $0,86 \%$ declarou que a mãe é Analfabeta.

Os pais detentores de diplomas universitários, segundo Dubar (2005), têm maiores perspectivas de que os filhos obtenham diplomas de ensino superior, considerando o elevado volume de capital cultural dos pais graduados, investidos nos filhos. Os dados desta pesquisa indicam que 46,5\% dos pais e 49,8\% das mães dos estudantes investigados são detentores de altos níveis de escolarização (ensino superior e pós-graduação), incidindo, como capital cultural, na perspectiva escolar dos estudantes para o ensino superior.

Questionados sobre a renda familiar, observou-se que na área Biológica há maior número de famílias $(35,8 \%)$ com renda familiar entre três e cinco salários mínimos ${ }^{4}$. As menores rendas familiares dos estudantes se concentram no grupo de alunos da área de Humanas, pois 17,9\% dos estudantes desta unidade acadêmica revelaram possuir renda familiar de até dois salários mínimos. Já os estudantes da área Tecnológica possuem a maior porcentagem $(19,4 \%)$ de renda familiar acima de 15 salários mínimos.

No que se refere à renda própria dos estudantes participantes da pesquisa, os estudantes que declararam, em maior número, não possuírem renda própria estão no Centro de Ciências relacionado à área Biológica, contando-se 58,9\% dos estudantes no universo de 39 participantes nesta Unidade Acadêmica.

Referindo-se aos estudantes que possuem renda própria com vínculo empregatício, destaca-se o Centro de Ciências relacionado à área de Humanas, com $20 \%$ dos participantes no universo de 40 estudantes que responderam à questão. Os estudantes de famílias de baixa renda necessitam subsidiar os estudos e, em poucos casos, como constatou Zago (2006), é possível obter ajuda familiar para tal.

A renda sem vínculo empregatício corresponde a atividades acadêmicas, tais como as bolsas de iniciação à docência, pesquisa, extensão ou estágios. Assim, o

\footnotetext{
4 Em 2012, o valor do salário mínimo era R\$622,00.
} 
vínculo a esses projetos que disponibilizam bolsas podem ser analisados como constituidores da formação do estudante, como também fonte de auxílio/manutenção de renda. As famílias cujos estratos sociais são desfavorecidos se esforçam para investirem mais no ensino do que as famílias de estratos sociais elevados, segundo a pesquisa realizada por Cabrito (2004), além de que os custos mensais efetuados pelos estudantes diminuem se comparado às classes alta e baixa.

Essa análise pode ser elucidada se comparada à renda familiar dos estudantes da área de Humanas junto ao número de estudantes desta unidade acadêmica que trabalham com vínculo empregatício. Há 61,5\% dos estudantes com rendas familiares mensais de até cinco salários mínimos e $20 \%$ dos estudantes com vínculo empregatício. Se compararmos aos estudantes do Centro de Ciências relacionado à área Biológica, 37,5\% dos estudantes possuem rendas familiares mensais de até cinco salários mínimos e nenhum estudante possui vínculo empregatício. Referindo-se aos estudantes do Centro de Ciências relacionado à área Tecnológica, tem-se que 16,6\% estudantes possuem rendas familiares mensais de até cinco salários mínimos e 7,5\% estudantes possuem vínculo empregatício.

A pesquisa realizada por Cabrito (2004) também indicou que grande parte dos estudantes universitários de instituições públicas pertence às classes mais favorecidas da sociedade $(46,6 \%)$. Se somada as rendas dos estudantes apresentadas anteriormente, tem-se que $60,51 \%$ dos estudantes investigados possuem rendas familiares acima de seis salários mínimos.

Com relação à sua trajetória escolar, os estudantes foram questionados sobre o tipo de instituição frequentada, em maior parte, nos ensinos fundamental e médio. No ensino fundamental, 50\% dos estudantes cursaram a escola pública. Já no ensino médio, $58,3 \%$ dos participantes frequentaram escolas privadas.

No que se refere às Ações Afirmativas para o ingresso ao ensino superior, 23,3\% dos estudantes usufruíram de algum tipo de Ação Afirmativa. Os dados revelam que o maior número de alunos que se utilizou de Ações Afirmativas se concentra na área de Humanas. Para Moehlecke (2004), os estudantes que utilizam de Ações Afirmativas detém características como persistência e perseverança perante as profecias que se autocumprem deparadas em suas trajetórias de vida.

Os estudantes foram questionados sobre a participação em grupos formais e informais pertencentes à universidade pesquisada, a fim de se conhecer as sobreposições do habitus e produção do capital cultural construído na universidade. Dos 120 
estudantes que responderam à questão, 65,8\% afirmaram não terem participado de grupos informais. Questionados sobre a participação em Diretórios Acadêmicos, 87,2\% dos estudantes não participaram.

No espaço institucional de formação, os atores sociais necessitam ser compreendidos como sujeitos sócio-históricos cuja construção e possibilidade de ação são determinadas pelo habitus que se constitui a partir de suas condições materiais de existência. Para Nogueira (2006), “a produção simbólica de um indivíduo ou grupo está subordinada, ou mesmo determinada pelas suas condições materiais de existência" (p.45). O habitus adquirido pelo indivíduo interfere diretamente em suas ações no campo.

Assim, o envolvimento dos alunos nos diversos grupos instituídos na universidade traduz a trajetória do estudante no que se refere às expectativas trazidas pelo capital cultural construído durante a vida do mesmo. As condições sociais de existência produzem as expectativas no estudante. Quando o estudante participa ou não de um determinado grupo há uma trajetória sendo construída e/ou legitimada; "a socialização produz o pertencimento de classe dos indivíduos reproduzindo a classe como grupo que partilha o mesmo habitus" (DUBAR, 2005, p. 85).

A socialização na universidade é produzida a partir do que o estudante traz consigo e, ao mesmo tempo, é produtora da formação profissional do mesmo. Os dados desta pesquisa revelam o baixo índice de participação em grupos universitários caracterizados como formais e informais. De certa maneira, os estudantes estão abdicando das relações que poderiam ser estabelecidas nesses grupos, tais como as relações de amizade, militância, afeto, desenvolvimento de competências, entre outras. Este fato sinaliza uma possível ampliação do individualismo que está fundamentado na competição no campo universitário, numa disputa de posição que este agente ocupa nas hierarquias instituídas.

Nas posições assumidas pelos sujeitos nos espaços sociais, o conceito de campo traz a compreensão de certos espaços de disposições sociais, nos quais determinado tipo de bem é produzido, consumido e classificado. Esse conceito representa, ainda, o espaço social de dominação e de conflitos, tendo cada um sua autonomia e sendo detentor de suas próprias regras de organização e hierarquia social. Para que um campo tenha êxito, faz-se necessário a existência de elementos de disputa e pessoas aptas na disputa do jogo, detentoras de habitus que reconheça e considere as regras inerentes ao jogo e os objetos de disputas (BOURDIEU, 1983). 
Segundo o Relatório Anual de Atividades da instituição pesquisada, 781 alunos estiveram envolvidos com Iniciação Científica (IC) em 2009, o que representa $10 \%$ do universo de estudantes matriculados naquele ano. Ressalta-se que a amostra de participantes envolve todos os alunos da instituição, desde os ingressantes aos que estavam se formando. Na presente pesquisa, $57,9 \%$ dos alunos se envolveram com a IC, entretanto nossa amostra inclui apenas estudantes matriculados nos dois últimos anos letivos, o que aumenta a possibilidade do aluno já ter realizado IC, se comparado ao aluno iniciante.

Em relação à participação em Projetos de Extensão, o mesmo Relatório de Atividades da instituição de ensino superior pesquisada, referente ao ano de 2009 , afirmou que 785 estudantes participaram desta atividade, o que corresponde a 10,1\% dos estudantes matriculados. Em nossa pesquisa, os dados indicam que $32,4 \%$ dos estudantes investigados participaram de Projetos de Extensão, no universo de 114 que responderam à questão.

Com relação à participação dos estudantes em Eventos Científicos, verifica-se que a maior participação é de estudantes da área Biológica (82,5\%), índice maior que a média geral da Instituição $(62,5 \%)$.

Os estudantes foram também interpelados sobre a realização de estágios curriculares e extracurriculares, sendo que $57,2 \%$ dos participantes não realizaram estágios curriculares e 72,8\% não fizeram estágio extracurricular. Os estágios permitem que o aluno desenvolva competências gerais fundamentais para a atuação nas diferentes circunstâncias da atividade profissional, o que torna a prática do estágio de suma importância para a formação do estudante (BENITO, 2012).

Portanto, observa-se nos dados apresentados que a maior renda familiar se concentra no grupo de estudantes pertencentes à área Tecnológica e a amostra que mais usufruiu de Ações Afirmativas no ingresso ao ensino superior e que possui menor renda familiar pertence à área de Humanas.

Os pais dos estudantes investigados são detentores de altos níveis de escolarização, o que influencia na escolha dos estudantes em cursar o ensino superior. Dentre as atividades desenvolvidas pelos estudantes observa-se maior ênfase atribuída às atividades de pesquisa científica.

A produtividade acadêmica dos estudantes universitários investigados foi também interpelada. Os alunos foram questionados sobre a publicação de trabalhos científicos e a quantidade de trabalhos que foram publicados, aproximadamente. Dos 
estudantes pesquisados, $72,5 \%$ não possuem trabalhos científicos publicados. No entanto, existe um significativo índice de trabalhos publicados nas áreas de Humanas e Tecnológica, ambas com 32,5\%.

Quando os alunos foram questionados se poderiam ter tido mais publicações, $61,4 \%$ dos estudantes afirmaram que poderiam, sim, ter mais publicações. Os motivos pelos quais os alunos afirmaram que poderiam ter publicado mais perpassaram às questões de falta de tempo, falta de estrutura da instituição, falta de interesse do aluno, dificuldade de escrever trabalhos científicos e de realizar a pesquisa na área pretendida, mau planejamento, e por fim, referiram-se aos dados que ainda serão publicados, uma vez que as pesquisas se iniciaram recentemente. Ademais ressaltaram a importância dessa atividade para a formação acadêmica. De maneira diversa às demais respostas, alguns alunos indicaram a não exigência de publicações de trabalhos científicos nas grades curriculares dos cursos de graduação.

Os participantes da pesquisa avaliaram suas produções acadêmicas em positiva, negativa ou em parte. Dos 101 estudantes que responderam a essa questão, 57,4\% consideraram suas produções acadêmicas positivas, 10,8\% avaliaram de maneira negativa e 31,6\% estudantes avaliaram como em parte. Questionados sobre o motivo das avaliações negativas e em parte realizadas, os estudantes disseram que poderiam ter se dedicado mais, faltou incentivo da universidade, falta de aplicação da pesquisa, falta de oportunidade e interesse, má vontade de alguns professores, falta de planejamento das atividades. Já para as avaliações consideradas positivas, os estudantes afirmaram que esta se deu porque se dedicaram de maneira suficiente à universidade, pelo grande aprendizado que obtiveram, pelo auxílio dos bons professores e tutores, pela realização no curso e na área de pesquisa, pelo bom desempenho acadêmico, pela abertura de oportunidades no exterior e, por fim, pela relevância acadêmica e social proporcionada pela pesquisa.

O levantamento bibliográfico sobre a atividade de IC no Brasil realizado por Massi e Queiroz (2010) aponta a IC como atividade de formação do universitário, evidenciando que o aluno que faz a IC tem melhor aproveitamento no curso de graduação e é mais valorizado. Caracterizando algumas particularidades do desenvolvimento da produção acadêmica do aluno, autenticando as avaliações positivas dos alunos questionados neste trabalho, encontra-se a socialização profissional, a nova visão da ciência, desenvolvimento pessoal e melhor desempenho na graduação. 
A sociabilidade tem como seu princípio gerador a atividade, pois enxerga nela o próprio processo de produção do homem, como um interminável processo de mudança do ambiente natural e humano e a contínua criação de interposições postas no processo de atividade (FREDERICO, 2009). Entendemos, portanto, a atividade discente como "trabalho, o meio pelo qual, se realiza a autoprodução do homem no interior da alienação" (FREDERICO, 2009, p.172). Apropriamo-nos do conceito de alienação (MARX, 1989) como a inobservância ao resultado das ações no processo de atividade discente, relacionando-se ao produto desse processo com estranhamento. Assim, entendemos que a alienação não se manifesta somente no resultado, mas também no interior do processo de produção da atividade do estudante universitário.

É possível identificar quais as atividades de maior predominância no decurso discente: $62,5 \%$ dos estudantes participaram de eventos científicos, 57,9\% dos estudantes participaram de programas de IC, 42,8\% fizeram estágios curriculares, $34,1 \%$ participaram de grupos informais (maior parte em grupos esportivos), 32,4\% dos estudantes se envolveram em Projetos de Extensão, 27,8\% fizeram estágios extracurriculares e 12,7\% participaram de diretórios acadêmicos.

É claro o maior índice de participação dos estudantes em eventos científicos e em programas de IC, o que corrobora a concepção de que a universidade tem valorizado a pesquisa em detrimento das outras atividades acadêmicas. A intensificação da atividade de pesquisa na instituição universitária se fundamenta na lógica do setor privado operando como instrumento benfeitor na ação produtiva, numa concepção de que esse setor é mais eficiente do que o Estado.

Assim, conforme já assinalado por Catani, Dourado e Oliveira (2001) o crescimento científico da universidade admitida numa política pragmática e materialista adequa a educação superior ao mercado. As regras e as normas desse mercado são impostas sobre a educação com critérios e resoluções que seguem a ordem de eficiência, rentabilidade, produtividade e competitividade, seguindo a racionalidade funcionalista da política neoliberal. A educação é compreendida como um generoso campo de lucros e rendas. Nesse sentido, o Estado reduz os investimentos e os gastos e fortalece seu poder fiscalizador, responsabilizando a universidade pela eficiência e rentabilidade, além de gerar a competitividade (DIAS SOBRINHO, 2001, p.160).

O interesse da universidade se volta, portanto, para a elevação da produtividade. Essa ideologia realiza transformações no ensino, no que se refere ao currículo, às atividades didático-pedagógicas, à profissionalização e submete a pesquisa ao preceito 
do utilitarismo emergente demandado, sobretudo, pela empresa. A autonomia da universidade é colocada em segundo plano. Isto porque o Estado se alocou absorvendo tecnologias e inovações tecnológicas das próprias universidades públicas com inferência financeira através de recursos oriundos do fundo público estatal, mediante os programas de incentivo à pesquisa e desenvolvimento que beneficia as empresas de capital nacional e internacional (SGUISSARDI; SILVA JÚNIOR, 2009).

O compromisso da universidade se concentra na relação de indissociabilidade no fazer institucional do ensino, da pesquisa e da extensão, compondo os três pilares que a identificam como fonte geradora de desenvolvimento. Assim, as relações de dominação políticas e econômicas estabelecidas e legitimadas na sociedade refletem, no plano ideológico, as interações de mecanismos da superestrutura da universidade.

O Estado considera fundamental garantir que o ensino superior ministrado seja eficiente para a ótica neoliberal. Para tanto, assegura que as universidades obtenham a excelência na formação profissional, atendendo à expectativa dos governos e sociedade civil de que a universidade forme profissionais altamente capacitados e aptos a atuarem no mercado de trabalho de maneira competitiva, eficaz e rápida. Os governos e empresários esperam que a universidade devolva à sociedade pessoas preparadas para acompanhar as necessidades e mudanças do mercado de trabalho e a necessidade da economia de maneira eficiente (CABRITO, 2004).

Concomitantemente, a formação do estudante universitário é construída nas atividades de ensino, pesquisa e extensão. Se há maior ênfase em um dos pilares, o tripé se sustenta de maneira desigual, causando um impacto diferenciado na formação do estudante. Assim, tendo maior sustentação nas atividades de pesquisa científica, a formação do estudante tende a se constituir na carreira de pesquisador.

A participação dos estudantes nas atividades relacionadas à pesquisa científica pode; ser analisada, bem como considerou Silva Jr. (2008), como coprodutores das inovações científicas produzidas na universidade. Os alunos geram inovações tecnológicas e, inseridos na universidade enquanto receptores, tornam-se contraditoriamente - altamente lucrativos para o mercado por gerar inovações técnicocientíficas sob baixo custo. Portanto, o aluno se torna mão de obra qualificada e barata para a produção científica.

\section{Considerações finais}


Em síntese, podemos afirmar que o presente estudo revela importantes discussões sobre a problemática institucional abarcada pela universidade.

O estudante exerce diversas atividades, construindo ao longo do percurso da graduação sua formação acadêmica e, consequentemente, sua carreira profissional. $\mathrm{O}$ compromisso social da universidade se caracteriza pela formação de profissionais aptos a desenvolverem (variadas) atividades profissionais qualificadas. A formação integral do estudante deve ser construída socialmente no contexto universitário e resulta da interação estudante-universidade, compreendida nos diversos espaços oportunizados pela instituição educativa de ensino superior.

A socialização dos estudantes universitários se dá na incorporação duradoura do habitus como uma impregnação de maneiras subjetivas procedentes dos grupos de pertença. A essência do grupo a que pertence o estudante pode ser manifestada de maneira distinta e adaptada às situações inesperadas (DUBAR, 2005).

Constatamos que a formação social, cultural e política do estudante universitário estão deficitárias, considerando a baixa inserção nos grupos formais e informais, além do pequeno índice de realização de estágios curriculares e extracurriculares. A ênfase atribuída às atividades de pesquisa científica compõe a formação do estudante à carreira de pesquisador, destituindo a universidade de seu compromisso social de formar integralmente no ensino, na pesquisa e na extensão. A mão de obra do estudante universitário é qualificada e de baixo custo para as empresas de capital nacional e internacional, podendo-se afirmar que a formação acadêmica do estudante, produzida na universidade, visa proporcionar condições técnicas relacionadas com a estrutura econômica da sociedade capitalista neoliberal.

AGRADECIMENTOS: Agência de Financiamento FAPESP - Fundação de Amparo à Pesquisa do Estado de São Paulo.

\section{REFERÊNCIAS}

BENITO, G. A. V. et al. Desenvolvimento de competências gerais durante o estágio supervisionado. Revista Brasileira de Enfermagem, v. 65, p. 172-178, 2012. Disponível em: < http://www.scielo.br/scielo.php?script=sci_arttext\&pid=S003471672012000100025\&nrm=iso>. Acesso em: 02 abr. 2013. 
CABRITO, B. G. O financiamento do ensino superior em Portugal: entre o Estado e o mercado. Educação e Sociedade, Campinas, v. 25, n. 88, p. 977-996, out. 2004. Disponível em: <http://www.scielo.br/scielo.php?script=sci_arttext\&pid=S010173302004000300016\&lng=pt\&nrm=iso >. Acesso em: 04 mar. 2013.

CARDOSO, R. C. L; SAMPAIO, H. Estudantes universitários e o trabalho. Revista Brasileira de Ciências Sociais, 1994. Disponível em:

http://www.anpocs.org.br/portal/publicacoes/rbcs_00_26/rbcs26_03.htm. Acesso em: 25 fev. 2013.

CATANI, A. M.; DOURADO, L. F. e OLIVEIRA, J. F. de. Natureza jurídica, organização acadêmica e gestão universitária. In: SGUISSARDI, V.; SILVA JÚNIOR, J. dos R. (org). Educação Superior: análises e perspectivas de pesquisa. São Paulo: Xamã, 2001. p. 69-80.

CHAUÍ, M. de S. Escritos sobre a Universidade. São Paulo: UNESP, 2001.

DIAS SOBRINHO, J. Avaliação ética e política em função da educação como direito público ou como mercadoria? Educação e Sociedade, Campinas, v. 25, n. 88, p. 703725, out. 2004. Disponível em:

$<$ http://www.scielo.br/scielo.php?script=sci_arttext\&pid=S0101-

$73302004000300004 \& \operatorname{lng}=$ pt\&nrm=iso>. Acesso em 11 maio 2013.

DIAS SOBRINHO, J. Concepções de universidade e de avaliação institucional. In: TRINDADE, H. (Org.). Universidade em ruínas: na república dos professores. RJ: Vozes/ Rio Grande do Sul: Cipedes, 2001.

DUBAR, C. A socialização como incorporação dos habitus. In: DUBAR, C. A socialização: construção das identidades sociais e profissionais. São Paulo: Martins Fontes, 2005.

FREDERICO, C. O jovem Marx: 1843-1844 as origens da ontologia do ser social. 2 ed. São Paulo: Expressão Popular, 2009.

GUEDES, M. de C. A presença feminina nos cursos universitários e nas pósgraduações: desconstruindo a ideia da universidade como espaço masculino. História, Ciências, Saúde - Manguinhos, Rio de Janeiro, 2013.Disponível em: $<$ http://www.scielo.br/scielo.php?script=sci_arttext\&pid=S010459702008000500006\&1 ng=en\&nrm=iso $>$. Acesso em: 25 mar. 2013.

JOLY, M. C. R. A.; SANTOS, A. A. A.; SISTO, F. F. (Orgs.) Questões do cotidiano universitário. São Paulo: Casa do Psicólogo, 2005.

MARX, K. Manuscritos econômico-filosóficos. Lisboa: Edições 70, 1989.

MASSI, L.; QUEIROZ, S. L. Estudos sobre iniciação científica no Brasil: uma revisão. Cadernos de Pesquisa, São Paulo, v. 40, n.139, Abril de 2010. Disponível em: <http://www.scielo.br/scielo.php?script=sci_arttext\&pid=S010015742010000100009\&lng=en\&nrm=iso>. Acesso em: 25 fev. 2013. 
MERCURI, E.; POLYDORO, S. A. J. (Orgs.). Estudantes universitários: características e experiências de formação. Taubaté: Cabral Editora e Livraria Universitária, 2003.

NOGUEIRA, C. M. M.; NOGUEIRA, M. A. A sociologia da educação de Pierre Bourdieu: limites e contribuições. Educação \& Sociedade, Campinas, v. 23, n.78, Abr. 2002. Disponível em: <http://www.scielo.br/scielo.php?script=sci_arttext\&pid=S0101$73302002000200003 \& \operatorname{lng}=$ en\&nrm=iso>. Acesso em 04 abr. 2012.

NOGUEIRA, M. A.; NOGUEIRA, C. M. Bourdieu \& a Educação. Belo Horizonte: Autêntica, 2006.

OLIVEIRA, D. A. A reestruturação do trabalho docente: precarização e flexibilização. Educação \& Sociedade, Campinas, vol. 25, n. 89, p. 1127-1144, Set./Dez. 2004.

\section{OLIVEIRA, M. A; SARAIVA, A. C. L. C. O Ofício da Discência nas}

Representações Sociais de Estudantes Universitários. Relatório de Pesquisa. Viçosa, MG: FAPEMG, 2010.

PACHANE, G. G. A experiência universitária e sua contribuição ao desenvolvimento pessoal do aluno. In: MERCURI, E., POLYDORO, S. A. J. (Orgs.). Estudantes Universitários: Características e experiências de formação. Taubaté, Cabral Editora e Livro Universitário, 2003.

SETTON, M. da G. J. A socialização como fato social total: notas introdutórias sobre a teoria do habitus. Revista Brasileira de Educação, Rio de Janeiro, v.14, n. 41, ago.2009. Disponível em: <http://www.scielo.br/scielo.php?script=sci_arttext\&pid=S1413$24782009000200008 \& \operatorname{lng}=$ pt\&nrm=iso>. Acesso em 27 mar. 2013.

SGUISSARDI, V. O desafio da educação superior no Brasil: quais são as perspectivas? Avaliação (Campinas), v.05, n.02, p.07-24, Junho, 2000. Disponível em:

http://educa.fcc.org.br/scielo.php?script=sci_arttext\&pid=S1414$40772000000300002 \& \operatorname{lng}=$ pt\&nrm=iso. Acesso em: 12 mar. 2013.

SGUISSARDI, V. Modelo de expansão da educação superior no Brasil: predomínio privado/mercantil e desafios para a regulação e a formação universitária. Educação e Sociedade, Campinas, v. 29, n. 105, p. 991-1022, dezembro. 2008. Disponível em: $<$ http://www.scielo.br/scielo.php?script=sci_arttext\&pid=S0101$73302008000400004 \& \operatorname{lng}=$ t\&nrm=iso>. Acesso em: 04 abr. 2013.

SGUISSARDI, V.; SILVA JÚNIOR, J. dos R. Trabalho intensificado nas federais: Pós-graduação e produtivismo acadêmico. São Paulo: Xamã, 2009.

SILVA JUNIOR, J. dos R. Instituição escolar e trabalho docente. In: RODRIGUES, M. V.; ALMEIDA, M. de L. P. [et al.]. Políticas educacionais e formação de professores em tempos de globalização. Brasília: Liber Livro Editora, UCDB, 2008.

SILVA, E. P. e SILVA JUNIOR, J. R. Da avaliação heterônoma da pós-graduação à desumanização das relações de trabalho na instituição universitária pública. In: ROTHEN, J. C.; BARREYRO, G. B. (Orgs.). Avaliação da educação: diferentes abordagens críticas. São Paulo: Xamã, 2011. 
SILVA JUNIOR, J. R. Instituição escolar e trabalho docente. In: RODRIGUES, M. V.; ALMEIDA, M. de L. P. [et al.]. Políticas educacionais e formação de professores em tempos de globalização. Brasília: Liber Livro Editora, UCDB, 2008.

TEIXEIRA, M. A. P.; DIAS, A. C. G.; WOTHICH, S. H.; OLIVEIRA, A. M. Adaptação à universidade em jovens calouros. Psicologia Escolar e Educacional, Campinas, v. 12, n. 1, p. 185-202, 2008.

TRIVIÑOS, A. N. S. Introdução à pesquisa em ciências sociais: a pesquisa qualitativa em educação. São Paulo: Atlas, 2011.

ZAGO, N. Do acesso à permanência no ensino superior: percursos de estudantes universitários de camadas populares. Revista Brasileira de Educação, Rio de Janeiro, v. 11, n. 32, p 226-237, ago. 2006. Disponível em:

<http://www.scielo.br/scielo.php?script=sci_arttext\&pid=S1413-

$24782006000200003 \& \operatorname{lng}=$ pt\&nrm=iso>. Acesso em 27 mar. 2013

\section{Como referenciar este artigo}

OLIVERIA, Maísa Aparecida.; FERNANDES, Maria Cristina Silveira Galan. A atividade discente na universidade: caracterização dos estudantes e impactos da produtividade acadêmica. Revista Ibero-Americana de Estudos em Educação, Araraquara/SP, v. 11, n. 3, p.1423-1440, 2016. Disponível em: <https://dx.doi.org/10.21723/riaee.v11.n3.7179>. E-ISSN: 1982-5587.

Submetido em: 19/08/2014

Aprovação final em: 11/07/2016 